\title{
Microstructure characterisation of Inconel 718 after laser assisted turning
}

\author{
Tadeusz Chwalczuk ${ }^{1, *}$, Damian Przestacki ${ }^{1}$, Piotr Szablewski ${ }^{2}$ and Agata Felusiak ${ }^{1}$ \\ ${ }^{1}$ Poznan University of Technology, Piotrowo 3 St., 60-965 Poznan, Poland \\ ${ }^{2}$ The President Stanislaw Wojciechowski State University of Applied Sciences in Kalisz \\ Nowy Świat 4 St., 62-800 Kalisz, Poland
}

\begin{abstract}
The paper presents the discussion about the possibility of optimising heating and cutting parameters for turning under laser assisted machining (LAM) conditions. The samples of Inconel 718 after annealing and ageing were used. The laser heating experiments were carried out on the stand equipped with the $\mathrm{CO}_{2}$ molecular laser. Characterisation of samples was performed by an optical microscope, hardness measurements, scanning electron microscopy (SEM) to ensure the exact depth of heat affect zone range and to optimised further cutting parameters. Different absorbing layers for laser beam impact improvement were tested. Turning trials were performed with constant cutting speed $v_{c}=28 \mathrm{~m} / \mathrm{min}$ and feed $f$ $=0,2 \mathrm{~mm} / \mathrm{rev}$. The influence of depth of cut ap on microstructure and its properties were investigated. It was proven that for sequential LAM dendritic structure appears in the laser affected zone of the Ni-based alloy. Such microstructures cause better machinability of Inconel 718 due to surface softening.
\end{abstract}

\section{Introduction}

Hybrid techniques and laser assisted machining processes have enabled more and more effective implementation of technological requirements in recent years. Providing an additional heat source to the cutting zone, are no longer laboratory technologies and find more and more industrial applications [1-3]. The dynamically developing laser-assisted turning (LAT) enters the next development stages. The main problem occurs in the correlation of technological parameters on various quality indicators. The improvement of the effects of LAT is related to the area of technological and geometric variable parameters occurring in the cutting process [4-5], laser heating [6-9] and geometric variables defining the relationship between the place of beam incidence and material decohesion $[3,6,9]$. Better machinability indicator can be achieved by using two kinematic variations of the laser-assisted machining process: by thermal softening of the heated cutting layer and by changing the microstructure of the surface layer of the workpiece [3].

One of the groups of materials particularly susceptible to the assisted turning is nickel-based superalloys. Superalloys are high strength nickel alloys that can work at a temperature often exceeding even 0.7 of melting point, without creeping, corrosion or

*Corresponding author: tadeusz.chwalczuk@put.poznan.p1 
oxidation. They are characterized by high resistance to corrosion as well as heat resistance. Heat resistance is resistance to gases causing oxidation at a temperature higher than $600{ }^{\circ} \mathrm{C}$, and heat resistance it is defined as the ability to withstand loads not only at ambient temperature but also at high temperature, which results in resistance to deformation at temperatures above $600{ }^{\circ} \mathrm{C}[5,10-11]$.

The problem presented in this paper is connected with laser assisted turning in the sequential version. The laser beam melts the surface and in the next step cutting tool removes material. The first allows obtaining better microstructure regarding alloy's machinability. Inconel 718 is hard-to-machine material. The surface hardening during conventional turning [11-12] which causing poor process performance will be eliminated via LAT.

\section{Experiment}

Cylindrical samples of Inconel 718 alloy (Table 1) were carried out by laser heating, traditional machining and laser assisted turning. A Trumpf TLF 2600 Turbo $\mathrm{CO}_{2}$ laser with a nominal power of $2.6 \mathrm{~kW}$ and conventional lathe TUM 35D1 by Famot was used for the tests (Figure 1).

Table 1. Chemical composition of Inconel 718 (\%)

\begin{tabular}{|c|c|c|c|c|c|c|c|c|c|c|c|c|c|}
\hline $\mathrm{Ni}$ & $\mathrm{Cr}$ & $\mathrm{Nb}$ & $\mathrm{Mo}$ & $\mathrm{Ti}$ & $\mathrm{Al}$ & $\mathrm{Co}$ & $\mathrm{Mn}$ & $\mathrm{Si}$ & $\mathrm{Cu}$ & $\mathrm{C}$ & $\mathrm{P}$ & $\mathrm{S}$ & $\mathrm{Fe}$ \\
\hline 50 & 17 & 4,75 & 2,8 & 0,6 & 0,2 & $\max$ & $\max$ & $\max$ & $\max$ & $\max$ & $\max$ & $\max$ & bal. \\
-55 & -21 & $-5,5$ & $-3,3$ & $-1,2$ & $-0,8$ & 1,00 & 0,35 & 0,35 & 0,30 & 0,08 &, 015 &, 015 & \\
\hline
\end{tabular}

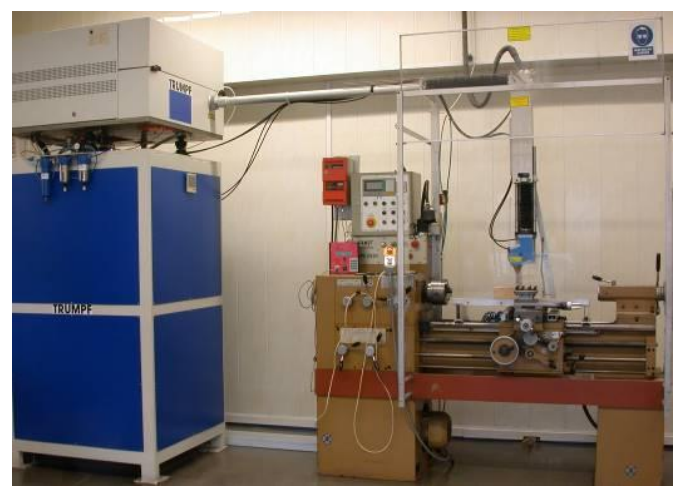

Fig. 1. Test stand for laser assisted turning.

The microstructure and hardness after the applied treatment or machining on the transverse specimen samples were investigated. The samples were cut correctly to prepare lateral decays and are included in the conductive resin. The samples were ground with abrasive paper of various granularity, polished with a suspension containing $\mathrm{Al}_{2} \mathrm{O}_{3}$ and digested to reveal the microstructure. The microstructure was analysed by light microscopy, and the hardness was determined by the Vickers method. Energy-dispersive X-ray spectroscopy studies were performed on heated laser samples.

The samples were heated with constant values of laser power density $D=1,53 \mathrm{~kW} / \mathrm{mm}^{2}$, laser spot value on the surface was $d_{l}=1 \mathrm{~mm}$, and the scanning speed on the surface was $v_{l}=5,75 \mathrm{~m} / \mathrm{min}$. Turning trials were performed with constant cutting speed $v_{c}=28 \mathrm{~m} / \mathrm{min}$ and feed $f=0,2 \mathrm{~mm} / \mathrm{rev}$. The influence of depth of cut $a_{p}$ on microstructure and its properties were investigated. 
Two different absorption layers were investigated. The first one was Gouache (called black layers), and Acheson LS2127 by Henkel Co. (called white layer) were used as cover layers. The layer thickness was approx. $30 \mu \mathrm{m}$. For metals, especially those with a smooth and unoxidized surface, the radiation absorption is low. The material is covered by a coating, and more specifically with absorption and protection layers. The protection of laser optics and a cutting tool is crucial when for a cylindrical surface the probability of reflection is greater. A reflected laser beam may cause increased temperature on the tool, or it may be the reason for the reduced durability of optical system mirrors.

\section{Results and discussion}

Microstructure optical observation proves that after laser heating the dendritic structure appears in the laser affected zone of Ni-based alloy (Fig. 2). The depth of the non-covered surface was approx. 300-350 $\mu \mathrm{m}$. For black and white layers the depth of dendritic structure was approx. 600 and $650 \mu \mathrm{m}$ respectively. The boundary between austenite and the malted zone is drowned undoubtedly.

a)

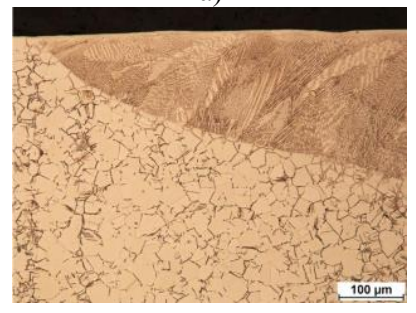

b)

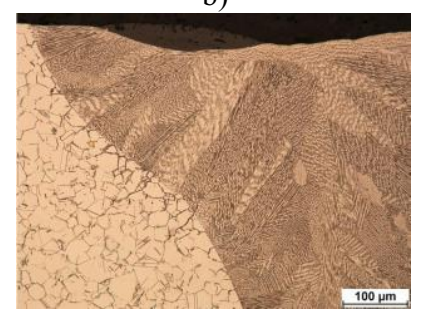

c)

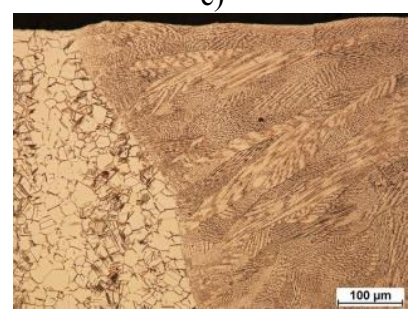

Fig. 2. The microstructure of Inconel 718 after heating with various absorption layers evaluation: a) pure surface, b) black cover, c) white cover.

Chemical composition was compared in the melted and base material. Two areas were selected as it is shown in Figure 3. EDS analysis shows that there are no significant changes in chemical component weight participation. The absorption layer was vaporised by laser heating as it should be.

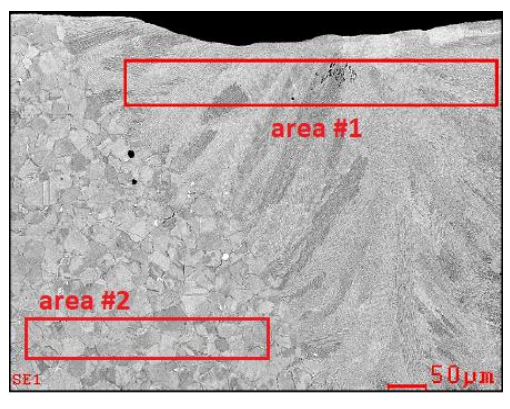

\begin{tabular}{|c|c|c|c|c|c|c|}
\hline \multirow{2}{*}{$\begin{array}{c}\text { Chemical } \\
\text { element/ } \\
\text { spectral line }\end{array}$} & \multicolumn{2}{|c|}{$\begin{array}{c}\text { pure surface, } \\
\text { area: }\end{array}$} & \multicolumn{2}{|c|}{$\begin{array}{c}\text { white layer, } \\
\text { area: }\end{array}$} & \multicolumn{2}{|c|}{$\begin{array}{c}\text { black layer, } \\
\text { area: }\end{array}$} \\
\cline { 2 - 7 } & $\# 1$ & $\# 2$ & $\# 1$ & $\# 2$ & $\# 1$ & $\# 2$ \\
\hline $\mathrm{Ni} / \mathrm{K}$ & 54,3 & 54,2 & 54,0 & 53,9 & 54,1 & 54,0 \\
\hline $\mathrm{Nb} / \mathrm{L}$ & 5,55 & 5,71 & 5,56 & 5,77 & 5,76 & 5,44 \\
\hline $\mathrm{Mo} / \mathrm{L}$ & 3,69 & 3,72 & 3,67 & 3,70 & 3,50 & 3,69 \\
\hline $\mathrm{Ti} / \mathrm{K}$ & 0,88 & 1,00 & 1,02 & 1,08 & 1,02 & 1,13 \\
\hline $\mathrm{Cr} / \mathrm{K}$ & 17,6 & 17,8 & 17,6 & 17,7 & 17,7 & 17,6 \\
\hline $\mathrm{Fe} / \mathrm{K}$ & 17,1 & 17,2 & 17,3 & 17,1 & 17,3 & 17,3 \\
\hline
\end{tabular}

Fig. 3. EDS analysis of chemical composition of the malted zone (area \#1) and core (area \#2) after laser heating for different absorption layers.

The Figure 4a shows the microstructure of the material without any laser treatment or machining. The Inconel 718 alloy was characterised by slightly smaller grain size at the surface compared to the grain observed in the core. The microstructure consists mainly of solid solution grains $\gamma$, as well as visible intermetallic phases, probably $\gamma^{\prime}$ and $\gamma^{\prime \prime}$. It is also possible to find a small number of carbides, borides or oxides. 
After laser assisted turning with laser density of $1,53 \mathrm{~kW} / \mathrm{mm}^{2}$, no significant differences were found in the microstructure compared to the untreated sample (Figure $4 \mathrm{~b}$ d), regardless of the depth of cut used. The significantly smaller grain size of the solid solution was found on the side of the treated surface compared to the core. The depth of cut in all cases exceeded the depth of the melted zone produced with the laser beam power applied. There is a certain probability of the white layer appearing and the surface of the machined material under LAM conditions. Such a layer is observed in machining technology in high loads and high-temperature presence.

a)

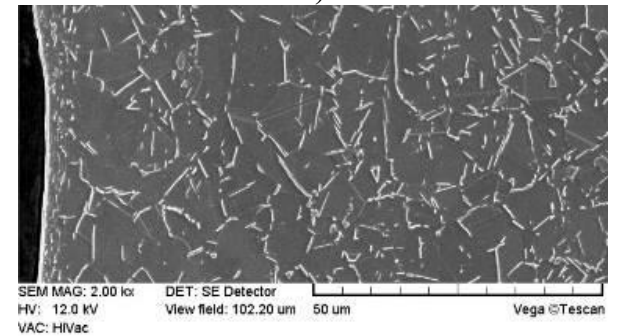

c)

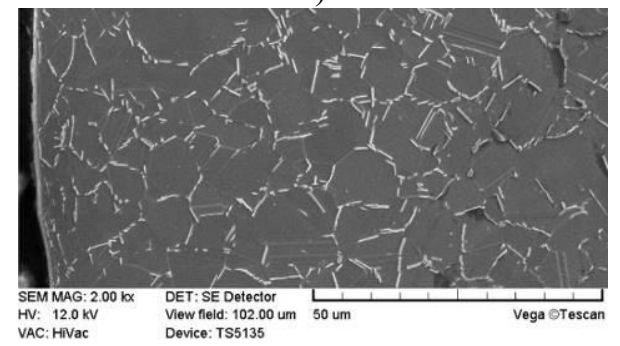

b)

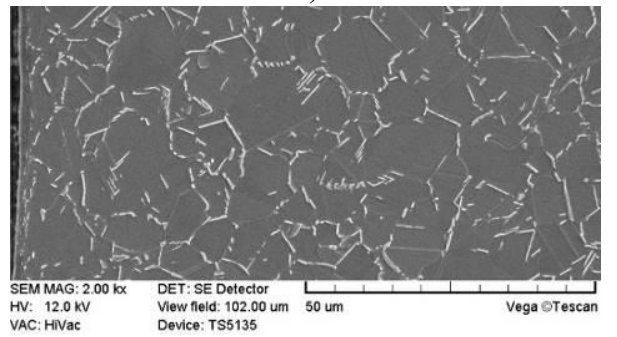

d)

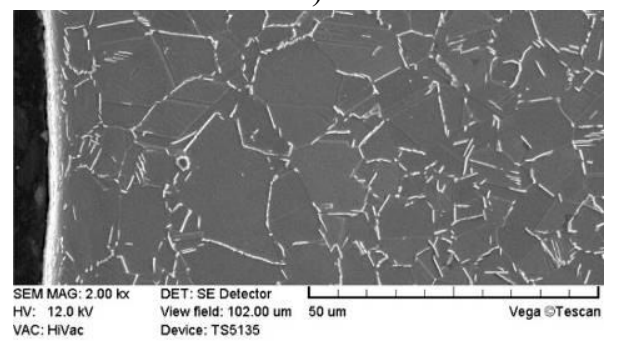

Fig. 4. Microstructures' SEM pictures of Inconel 718 after laser assisted turning for different depth of cut values: a) $a_{p}=0,20 \mathrm{~mm}$, b) $a_{p}=0,40 \mathrm{~mm}$, c) $\left.a_{p}=0,60 \mathrm{~mm} \mathrm{~d}\right) a_{p}=0,80 \mathrm{~mm}$.

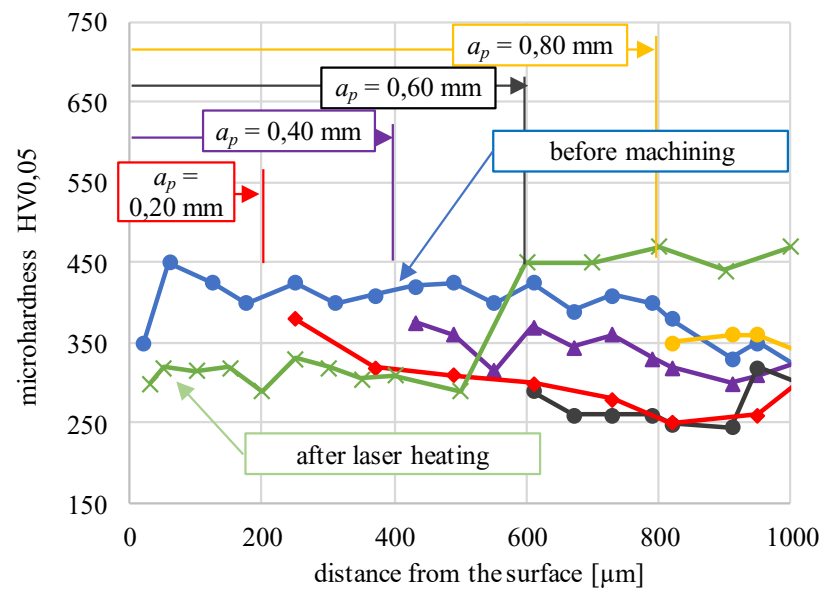

Fig. 5. Microhardness evaluation of Inconel 718 for various depth of cut $a_{p}$ values and nonmachined surface.

Samples subjected to laser heating followed by machining (LAT) were characterised by significantly lower hardness compared to the primary material (Figure 5). In the melted zone it was caused by the dissolution of the intermetallic phases $\gamma^{\prime}$ and $\gamma^{\prime \prime}$ in the solid solution $\gamma$. However, the decisive influence on reducing the hardness in the heat affected 
zone was probably an increase in grain size in this zone. At the same time, in the melted zone, the hardness was usually slightly higher than in the heat affected zone, which was influenced by the dendritic microstructure of the solid solution $\gamma$. The hardness values after laser assisted machining might be influenced by a lack of strengthen effect which occurs during conventional machining or different plastic-deformation-based process.

\section{Conclusions}

On the basis of the carried out investigations, the following conclusion is formulated:

- Surface hardness might be decreased via laser heating. Such an effect is strongly desired in metal machining.

- The depth of laser heat flux impact is strongly correlated with the presence of an absorbing layer. There are no significant differences in depth of dendritic structure creation among tested cover layers.

- After laser-assisted turning, no significant differences were found in the microstructure compared to the untreated sample, regardless of the depth of cut used.

- The significantly smaller grain size of the solid solution was found on the side of the treated surface compared to the core.

The presented research results, executed under the domestic project LIDER of No. 164/L6/14/NCBR/2015 with grants for education allocated by the National Centre for Research and Development.

\section{References}

1. D. Ulutan, T. Ozel, International Journal of Machine Tools and Manufacture, 51, pp 250-280 (2011)

2. M. Rybicki, P. Szablewski, MATEC Web of Conferences, 121, 03020 (2017)

3. D. Przestacki, T. Chwalczuk, MATEC Web of Conferences, 136, 02006 (2017)

4. P. Nieslony, W. Grzesik, P. Laskowski, Journal of Machine Engineering, 17, 3, 2017

5. W. Grzesik, P. Niesłony, W. Habrat, J. Sieniwaski, P. Laskowski, Tribology International, 118, pp 337-346 (2018)

6. A. Bartkowska, M. Kukliński, P. Kieruj, MATEC Web of Conferences, 121, 03006 (2017)

7. N. Makuch, P. Dziarski, M. Kulka, Journal of Achievements in Materials and Manufacturing Engineering, 83, 2, pp 67-78 (2017)

8. M. Frackowiak, N. Makuch, P. Dziarski, M. Kulka, S. Taktak, Advances in Manufacturing. Lecture Notes in Mechanical Engineering, pp 923-932 (2017)

9. D. Przestacki, M. Kukliński, A. Bartkowska, Int. J. Adv. Manuf. Technol., 93, 9-12, pp 3111-3123 (2017)

10. R. Jiang, X. Chen, R. Ge, W. Wang, G. Song, Chinese Journal of Aeronautics, 31, 1, pp 187-196 (2018)

11. A. Thakur, S. Gangopadhyay, International Journal of Machine Tools and Manufacture 100, 25 (2016)

12. X. Ren, Z. Liu, Int. J. Adv. Manuf. Technol., 86, 5-8, pp 2319-2327 (2016) 